\title{
DFT calculations on conjugated organic molecules based on thienothiophene for electronic applications
}

\author{
Ismail Elaati Allah ${ }^{12}$, Hsaine Zgou ${ }^{1 *}$, Abdelkrim AMKASSOU ${ }^{12}$, Hind LAFRIDI $^{12}$ \\ ${ }^{1}$ Polydisciplinary Faculty of Ouarzazate, Ibn Zohr University, Morocco \\ ${ }^{2}$ Faculty of Sciences Agadir, Ibn Zor University, Morocco
}

\begin{abstract}
We report theoretical studies on the optoelectronic structural properties of five thienothiophene (T) conjugated $\pi$ conjugates. The geometries, the prediction of the optoelectronic structural properties of the five compounds are studied by calculations of functional density theory (DFT). The absorption properties $\left(\lambda_{\max }, \mathrm{E}_{\mathrm{tr}}, \mathrm{f}\right)$ of molecules are gained by the (DFT) B3LYP / 6-31G (d) ZINDO method, so that the most occupied molecular orbitals (HOMO), the least molecular orbitals occupied (LUMO), the energy deficit being calculated using the factor Gaussian 09 and its GaussView 5.0.8 graphical interface.
\end{abstract}

Keywords: DFT; Structural properties; Optoelectronic properties; Thienothiophene; HOMO; LUMO; Gap.

\section{INTRODUCTION}

Organic photovoltaic tool have opened up the potential for producing light energy in a simple and economical way. The bilayer technology typically uses organic semiconductor cables intercalated between the anode and cathode electrodes, the first is an electron acceptor and the second is an electron donor [1-2]. In this work, we have based on unsubstituted thienothiophene (fig.1a) as a $\pi$ conjugated organic semiconductor. We mainly used DFT to study the optoelectronic and structural properties of the four molecules.

Thienothiophene often refers to all the structurally related thiophene derivatives with the given formula $\mathrm{C}_{6} \mathrm{H}_{4} \mathrm{~S}_{2}$. As for importance, they are: thiophene thieno (3,2-b), thieno (2,3-b) thiophene and thieno (3,4-b) thiophene. The other isomers are characterized by $\mathrm{S}$ (IV) and are less stable [3]. Thieno (2,3-b) thiophene was the series' first member of the series to be isolated.

The thienothiophene conjugate compounds have extensive delocalization of $\mathrm{n}$ electrons along the molecular backbone, making them attractive for various optoelectronic applications [4-5].

Because of this applicative interest and to that these shirt systems can be used as model compounds for the parent polymer, they have been extensively studied [6-7]. Also, because of their controllable and precisely defined structure, physical properties can be correlated with the conjugation length and the side chains. Therefor implementing these molecular structures by functionalization at the terminal and side positions permit their application as molecular materials in organic field-effect transistors [8-9], light-emittingdevices $[10,11,12,13]$,photovoltaic cells [14-15],or even as molecular wires for information storageor transfer [16-17].

Polymers and oligomers with low band gap are expected to show not only good intrinsic conductivity butalso nonlinear optical properties [18-19].For their successful design, it is vital to have a complete understanding of the relationship between electronic properties and the chemical structure of polymers [20-21]. Different routes are her followed for designing novel conducting polymers, one is provided by donor-acceptor polymers, based on the approach suggested for the first time by Havinga et al. [22]. The study of conjugated oligomers is very attractive for finitesize systems can be achieved with a well-defined chemical structure and high purity. This opens the way for the investigation of electronic properties as a function of chain length and extent of the parent $\pi$ electron system.

In this paper, we present a detailed study of DFT (B3LYP / 6-31 (d)) of the four thienothiophene compounds. We focus on the geometric structure of the compounds and the electronic properties. The chemical structure and optimized structures of the compounds studied are illustrated in FIG. 1 
a)

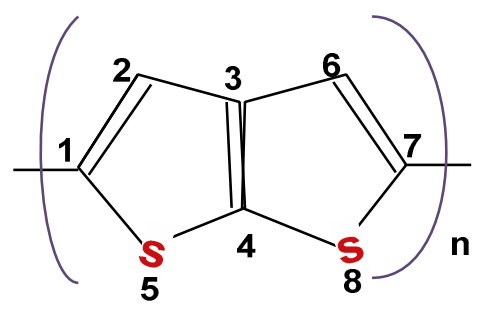

b)

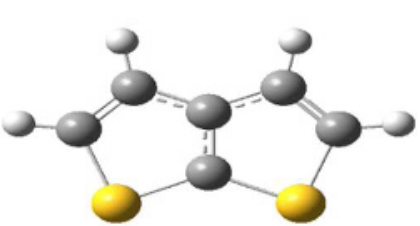

$\mathrm{T} 1$

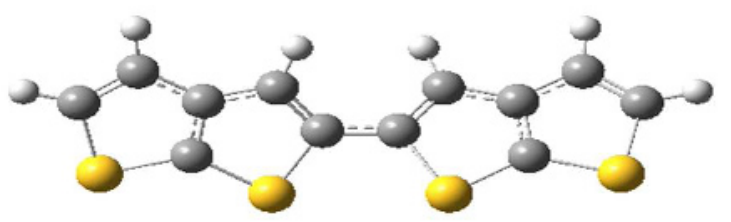

$\mathrm{T} 2$

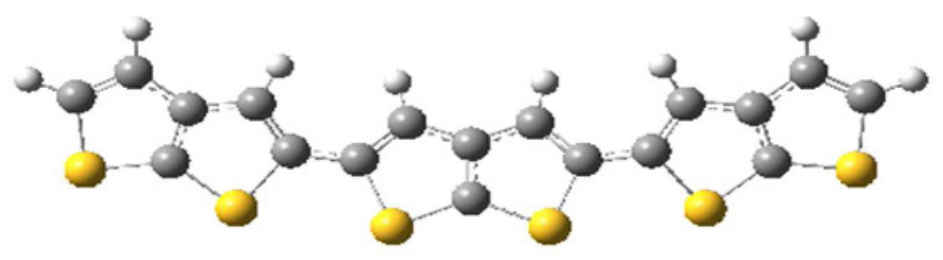

T3

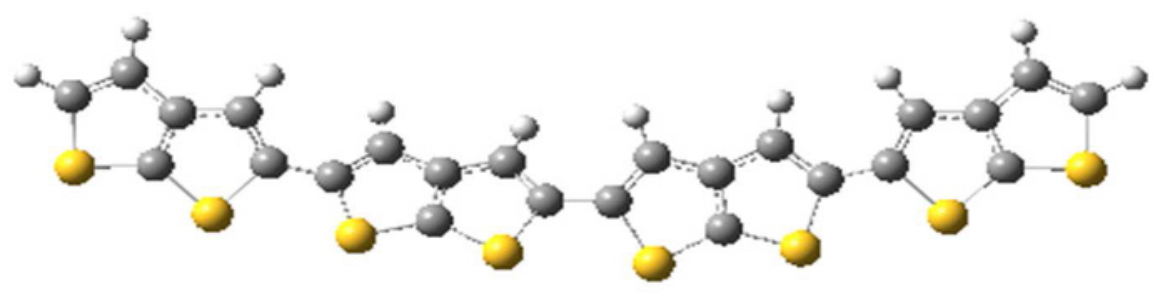

$\mathrm{T} 4$

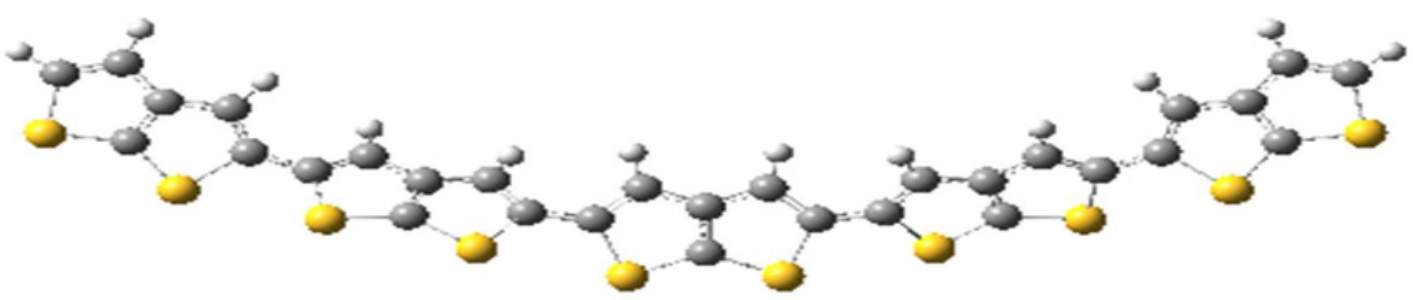

T5

Fig. 1. (a) Compounds chemical structures under investigation. (b) The compounds theoretical geometric structures of optimized by B3LYP/6-31G (d).

The general abbreviation of our studied compounds is T1 (Monothienothiophene), T2 (Dithienothiophene), T3 (Trithienothiophene), T4 (Tetrathienothiophene) and T5 (Pentathienothiophene) thienothiophene, varies between 1 and 5. 


\section{Calculation methodology}

The calculations done on the geometries of the four molecules were carried out under functional density theoretical theory (DFT) B3LYP and the set of bases 6-31G (d) [23]. The notation B3 indicates a parameter with three parameters of Becke [24] and

\section{Results and discussion}

\subsection{Geometric structure results}

The optimized geometries of the five compounds (T1, T2, T3, T4 and T5) obtained at B3LYP / 6-31G (d) are shown in FIG. 1 b.
LYP indicates the function Lee - Yang - Parr [25]. Calculations were given using the Gaussian 09 program. All structures are fully optimized by B3LYP/6-31G (d) without any constraint.

The calculated lengths di ( $\mathrm{i}=1$ to 29$)$ and the dihedral angles $\Theta \mathrm{i}$ ( $\mathrm{i}=1$ to 4 ) of the interatomic bonds are presented in FIG. 2 and their optimized values are summed up in Tables 1 and 2 respectively.<smiles></smiles>

Fig. 2. Marked bond lengths and dihedral angles.

Table 1. The bond length values $(\AA)$ of the examined molecules.

\begin{tabular}{|c|c|c|c|c|c|}
\hline $\begin{array}{c}\text { Molecules } \\
\text { Inter-atomics distance }\end{array}$ & T1 & $\mathrm{T} 2$ & T3 & T4 & T5 \\
\hline $\mathrm{d}_{1}$ & 1.36052 & 1.36002 & 1.35998 & 1.36191 & 1.35994 \\
\hline$d_{2}$ & 1.44337 & 1.44391 & 1.44391 & 1.43600 & 1.44389 \\
\hline $\mathrm{d}_{3}$ & 1.38669 & 1.38756 & 1.38773 & 1.39277 & 1.38773 \\
\hline $\mathrm{d}_{4}$ & 1.44337 & 1.43647 & 1.43627 & 1.43001 & 1.43611 \\
\hline $\mathrm{d}_{5}$ & 1.36052 & 1.37118 & 1.37141 & 1.37259 & 1.37142 \\
\hline $\mathrm{d}_{6}$ & & 1.44127 & 1.44098 & 1.45197 & 1.44100 \\
\hline $\mathrm{d}_{7}$ & & 1.37118 & 1.37083 & 1.37220 & 1.37075 \\
\hline $\mathrm{d}_{8}$ & & 1.43647 & 1.43708 & 1.43065 & 1.43709 \\
\hline $\mathrm{d}_{9}$ & & 1.38757 & 1.38837 & 1.39319 & 1.38839 \\
\hline $\mathrm{d}_{10}$ & & 1.44390 & 1.43708 & 1.43042 & 1.43681 \\
\hline $\mathrm{d}_{11}$ & & 1.36002 & 1.37082 & 1.37245 & 1.37091 \\
\hline $\mathrm{d}_{12}$ & & & 1.44097 & 1.45163 & 1.44085 \\
\hline$d_{13}$ & & & 1.37140 & 1.37249 & 1.37087 \\
\hline $\mathrm{d}_{14}$ & & & 1.43627 & 1.43040 & 1.43686 \\
\hline $\mathrm{d}_{15}$ & & & 1.38773 & 1.39323 & 1.38844 \\
\hline$d_{16}$ & & & 1.44391 & 1.43062 & 1.43686 \\
\hline$d_{17}$ & & & 1.35998 & 1.37222 & 1.37087 \\
\hline $\mathrm{d}_{18}$ & & & & 1.45189 & 1.44085 \\
\hline $\mathrm{d}_{19}$ & & & & 1.37264 & 1.37091 \\
\hline $\mathrm{d}_{20}$ & & & & 1.43002 & 1.43681 \\
\hline $\mathrm{d}_{21}$ & & & & 1.39276 & 1.38839 \\
\hline $\mathrm{d}_{22}$ & & & & 1.43600 & 1.43708 \\
\hline $\mathrm{d}_{23}$ & & & & 1.36191 & 1.37077 \\
\hline $\mathrm{d}_{24}$ & & & & & 1.44100 \\
\hline$d_{25}$ & & & & & 1.37144 \\
\hline $\mathrm{d}_{26}$ & & & & & 1.43610 \\
\hline $\mathrm{d}_{27}$ & & & & & 1.38773 \\
\hline $\mathrm{d}_{28}$ & & & & & 1.44390 \\
\hline $\mathrm{d}_{29}$ & & & & & 1.35994 \\
\hline
\end{tabular}


The interatomic distances (di) take small values for di ( $i=1,3,5,7,9,11,13,15,17,19,21,23,25,27$, 29) and high values for di ( $\mathrm{i}=2,4,6,8,10,12,14$, $16,18,20,22,24,26,28)$. The inter-ring distances di $(i=6,12,18)$ take the highest value which is close to $1.45 \AA$. This implies that these links are sometimes simple and sometimes double, thus favoring a good delocalization and combination of $\pi$ electrons.

Table 2. The dihedral angles $\left(^{\circ}\right)$ of the compounds examined.

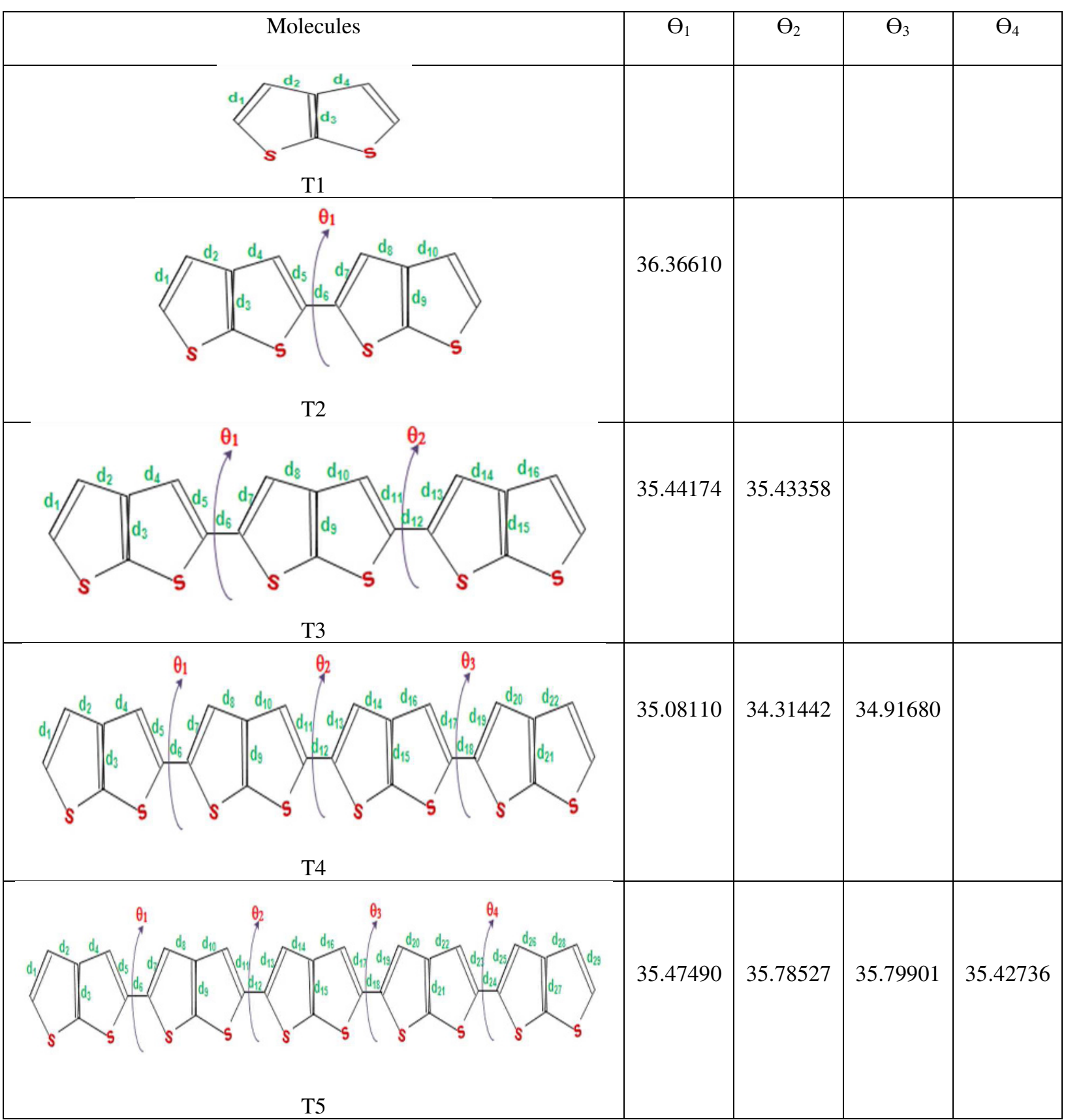

For the two systems (T2 and T3), we observe a great deference in the optimized binding angle $(\Theta 1)$ when we add thienothiophene (T) compound, but for T3,
T4 and T5 the optimized binding angles ( $\Theta 1$ and $\Theta 2)$ since they remain constant. 


\subsection{Electronic properties of the compounds examined}

The electronic properties depend essentially on the fundamental and excited states. The lowest unoccupied molecular orbital (LUMO) and the highest occupied molecular orbital (HOMO). The gap energy is calculated by the difference between the LUMO and HOMO levels, their values for all the molecules examined are shown in Table 3 . Calculations have been achieved by the method B3LYP / 6-31 (d).

Table 3. The energies of the compounds examined in (ev): Еномо, Elumo and Egap.

\begin{tabular}{|c|c|c|c|}
\hline Compound & $\mathrm{E}_{\mathrm{LUMO}}(\mathrm{ev})$ & $\mathrm{E}_{\mathrm{HOMO}}(\mathrm{ev})$ & $\mathrm{E}_{\mathrm{gap}}(\mathrm{ev})=\mathrm{E}_{\mathrm{LUMO}}-\mathrm{E}_{\mathrm{HOMO}}$ \\
\hline $\mathrm{T} 1$ & -0.624 & -6.180 & 5.556 \\
\hline $\mathrm{T} 2$ & -1.399 & -5.688 & 4.289 \\
\hline $\mathrm{T} 3$ & -1.514 & -5.585 & 4.071 \\
\hline $\mathrm{T} 4$ & -1.300 & -5.355 & 4.055 \\
\hline $\mathrm{T} 5$ & -1.594 & -5.538 & 3.944 \\
\hline
\end{tabular}

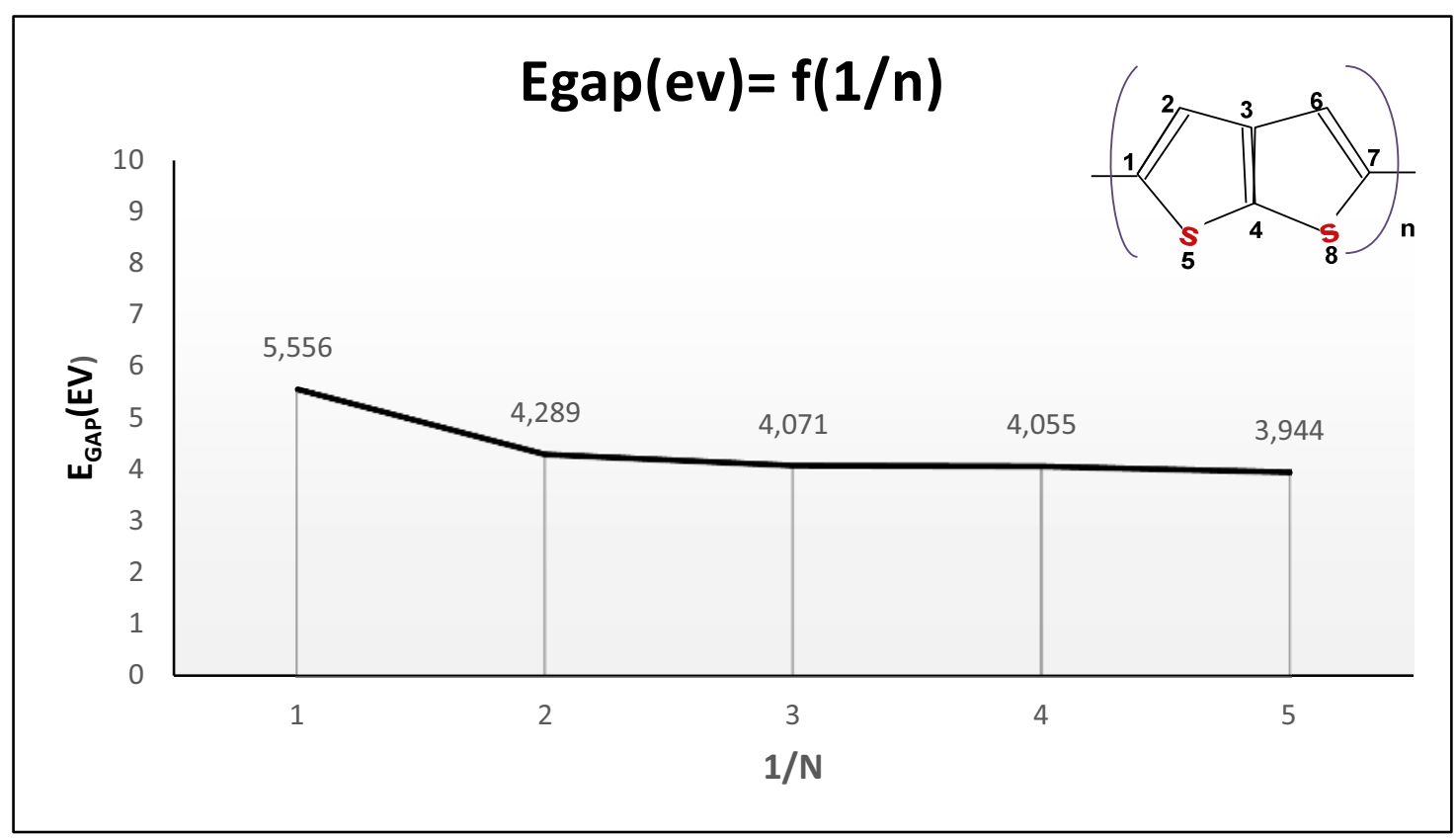

Fig 3. Band structure diagram illustrating the gap energy in function $1 / \mathrm{n}$ (1 to 5$)$.

In this result, we first observed that the synthesized molecules generally have a high gap energy, especially the molecule (T1) of $5.556 \mathrm{eV}$, but when we add a base $(\mathrm{T})$ the band gap decreased slightly for

\subsection{Electronic structures of the compounds examined}

In this section, we study the lowest virtual orbitals LUMO and highest occupied HOMO orbitals for these compounds, because the relative order of occupied and virtual orbitals give a reasonable qualitative indication of the excitation properties [26] and the capacity of electron transitions or whole transport. We plotted the contour curves of the LUMO and HOMO orbitals of five molecules (T1, all molecules, then the gap energy gap decrease of the molecule (T1) to (T5) from $5.556 \mathrm{eV}$ to 3.944 $\mathrm{eV}$.

T2, T3, T4 and T5) in their fully optimized conformation B3LYP / 6-31G (d) in FIG. 4 


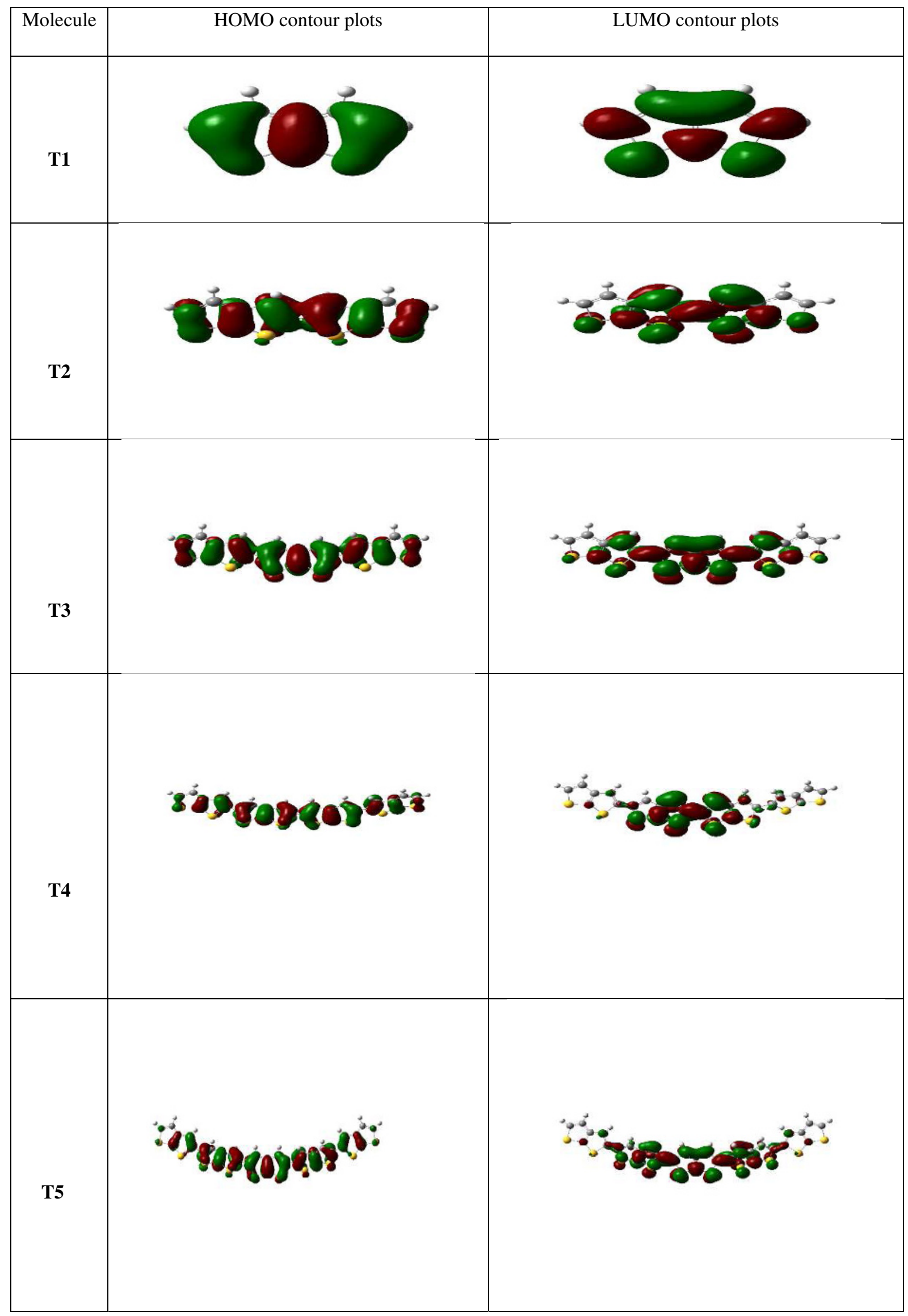

Fig. 4. The LUMO and HOMO orbitals of the four compounds (T1, T2, T3, T4 and T5) obtained by B3LYP / 6-31G (d). 
We observe that in the HOMO orbital the electron density is mainly distributed throughout the chain of compounds. However, it moves completely to the

\subsection{Absorption spectra}

The table 3 shows the vertical excitation energy Eex $(\mathrm{eV})$, the maximum absorption $\lambda \max (\mathrm{nm})$, and the acceptor unit in the case of LUMO. In the case of T5 the electron cloud are delocalized to the innermost ring in orbit LUMO.

oscillator strength (f) in all studied molecules. These properties are counted by the DFT-B3LYP/ 6-31G (d) ZINDO method.

Table 4. Calculated wavelength $\lambda$, Transition Energies and Oscillator Strengths (f) of the four compounds (T1, T2,

T3, T4 and T5) obtained by (DFT) B3LYP/6-31G (d) ZINDO method.

\begin{tabular}{|c|c|c|c|c|}
\hline Compound & $E_{e x}(e v)$ & $\lambda_{\max }(\mathrm{nm})$ & $f$ & Transition \\
\hline \multirow[t]{3}{*}{ T1 } & 3.9469 & 314.13 & 0.0478 & $\mathrm{HOMO} \rightarrow$ LUMO (0.68442) \\
\hline & 4.4539 & 278.37 & 0.0155 & $\mathrm{HOMO} \rightarrow \mathrm{LUMO}+2(0.69993)$ \\
\hline & 4.7053 & 263.50 & 0.1803 & HOMO-1 $\rightarrow$ LUMO $(-0.15176)$, HOMO $\rightarrow$ LUMO+1 (0.67453) \\
\hline \multirow[t]{3}{*}{$\mathbf{T 2}$} & 3.3350 & 371.77 & 0.4118 & HOMO-1 $\rightarrow$ LUMO+1 (-0.15240), HOMO $\rightarrow$ LUMO $(0.66777)$ \\
\hline & 3.8623 & 321.01 & 0.0888 & $\begin{array}{l}\text { HOMO- } 1 \rightarrow \text { LUMO (-0.37502), HOMO- } 1 \rightarrow \text { LUMO+2 (-0.17132) } \\
\text { HOMO } \rightarrow \text { LUMO+1 (0.52949) }\end{array}$ \\
\hline & 4.2448 & 292.08 & 0.5040 & $\begin{array}{l}\text { HOMO-1 } \rightarrow \text { LUMO+1 (-0.34244), HOMO-1 } \rightarrow \text { LUMO+3 (-0.11824) } \\
\text { HOMO } \rightarrow \text { LUMO+2 (0.57217) }\end{array}$ \\
\hline \multirow[t]{3}{*}{$\mathbf{T 3}$} & 3.2804 & 377.95 & 0.0245 & $\begin{array}{l}\mathrm{HOMO}-2 \rightarrow \text { LUMO+2(0.11121),HOMO-1 } \rightarrow \text { LUMO+1(-0.25489), } \\
\text { HOMO } \rightarrow \text { LUMO }(0.61551)\end{array}$ \\
\hline & 3.3270 & 372.66 & 1.0415 & $\begin{array}{l}\mathrm{HOMO}-1 \rightarrow \text { LUMO } \quad(-0.38114), \quad \mathrm{HOMO} \rightarrow \mathrm{LUMO}+1 \\
\mathrm{HOMO} \rightarrow \mathrm{LUMO}+3(0.11054)\end{array}$ \\
\hline & 3.8370 & 323.13 & 0.1262 & $\begin{array}{l}\text { HOMO-2 } \rightarrow \text { LUMO }(0.28946), \text { HOMO-2 } \rightarrow \text { LUMO+2 }(0.11835) \\
\text { HOMO- } \rightarrow \text { LUMO+1 (-0.37007), HOMO- } \rightarrow \text { LUMO+3 }(0.18639) \\
\text { HOMO } \rightarrow \text { LUMO+2 (0.39244), HOMO } \rightarrow \text { LUMO+4 }(0.14317)\end{array}$ \\
\hline \multirow[t]{3}{*}{ T4 } & 3.1207 & 397.30 & 0.7974 & $\begin{array}{l}\text { HOMO-2 } \rightarrow \text { LUMO }(0.12101), \text { HOMO- } \rightarrow \text { LUMO }(-0.32377) \\
\text { HOMO-1 } \rightarrow \text { LUMO+1 (0.17478), HOMO } \rightarrow \text { LUMO }(0.48842) \\
\text { HOMO } \rightarrow \text { LUMO+1 }(-0.19999), \text { HOMO } \rightarrow \text { LUMO+2 }(0.16608)\end{array}$ \\
\hline & 3.2732 & 378.79 & 0.3866 & $\begin{array}{l}\text { HOMO-2 } \rightarrow \text { LUMO }(-0.17502), \text { HOMO-2 } \rightarrow \text { LUMO+1 }(-0.12720) \\
\text { HOMO-2 } \rightarrow \text { LUMO+2 (0.17726), HOMO } 1 \rightarrow \text { LUMO+1 }(0.14429), \\
\text { HOMO } \rightarrow \text { LUMO }(0.30685), \text { HOMO } \rightarrow \text { LUMO+1(0.35463), } \\
\text { HOMO } \rightarrow \text { LUMO+2 (-0.35077) }\end{array}$ \\
\hline & 3.3141 & 374.11 & 0.6951 & $\begin{array}{l}\text { HOMO-2 } \rightarrow \text { LUMO+1 (0.15994), HOMO- } 1 \rightarrow \text { LUMO }(0.12835) \\
\text { HOMO- } \rightarrow \text { LUMO+1 (0.40327), HOMO- } 1 \rightarrow \text { LUMO+2 }(0.26868), \\
\text { HOMO } \rightarrow \text { LUMO+1 }(0.24586), \text { HOMO } \rightarrow \text { LUMO+2 }(0.29916)\end{array}$ \\
\hline \multirow[t]{3}{*}{ T5 } & 3.2550 & 380.90 & 0.0006 & $\begin{array}{l}\text { HOMO-3 } \rightarrow \text { LUMO+3 }(-0.13073), \text { HOMO-2 } \rightarrow \text { LUMO }(0.10505) \\
\text { HOMO-2 } \rightarrow \text { LUMO+2 }(0.20416), \text { HOMO- } \rightarrow \text { LUMO+1 }(-0.30423) \\
\text { HOMO } \rightarrow \text { LUMO }(0.52328)\end{array}$ \\
\hline & 3.2902 & 376.83 & 0.0357 & $\begin{array}{l}\text { HOMO-3 } \rightarrow \text { LUMO (-0.11026), HOMO-2 } \rightarrow \text { LUMO+1 (-0.12900) } \\
\text { HOMO-2 } \rightarrow \text { LUMO+3 (0.15357), HOMO- } \rightarrow \text { LUMO (-0.37323), } \\
\text { HOMO- } \rightarrow \text { LUMO+2(0.19083),HOMO } \rightarrow \text { LUMO+1(0.43955), } \\
\text { HOMO } \rightarrow \text { LUMO+3 (0.12714) }\end{array}$ \\
\hline & 3.3027 & 375.40 & 2.3232 & $\begin{array}{l}\text { HOMO-3 } \rightarrow \text { LUMO }(-0.21785), \text { HOMO- } \rightarrow \text { LUMO+1 }(0.28140) \\
\text { HOMO-1 } \rightarrow \text { LUMO+2 }(-0.34763), \text { HOMO- } \rightarrow \text { LUMO+6 }(0.10028), \\
\text { HOMO } \rightarrow \text { LUMO+3 }(0.43624), \text { HOMO } \rightarrow \text { LUMO+5 }(-0.10526)\end{array}$ \\
\hline
\end{tabular}

The compounds T1, T2, T3, T4 and T5, have absorption maxima $(\lambda \max )$ respectively at 314.13 $\mathrm{nm} 371.77 \mathrm{~nm}, 377.95 \mathrm{~nm}$ and $397.30 \mathrm{~nm}, 380.90$ $\mathrm{nm}$ reflecting the transition HOMO - LUMO. In addition, the absorption spectra simulated for all studied oligomers have a peak; this can be attributed to the charge transfer intermolecular band caused by acceptor unit introduced in the molecular structures. This indicates that these organic oligomers could absorbed the maximum amount of incident radiation light, especially $\mathrm{T} 4$ and $\mathrm{T} 5$ molecules. In the excitation state $\mathrm{S} 1$, it corresponds exclusively to the 
promotion of an electron from the HOMO to the LUMO. Moreover, the largest oscillation force ( $\mathrm{f}<1$ ) that comes from the S0 to $\mathrm{S} 1$ electronic transition.

T1

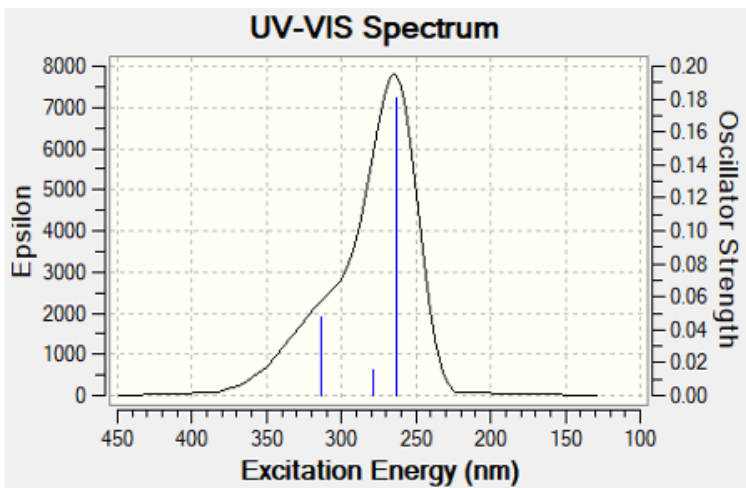

T3

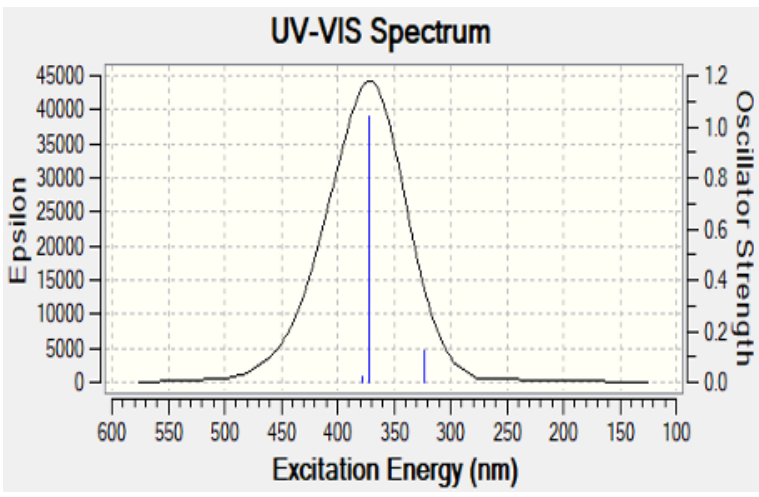

The simulated absorption spectra of the five compounds (T1, T2, T3, T4 and T5) are illustrated in FIG. 5.

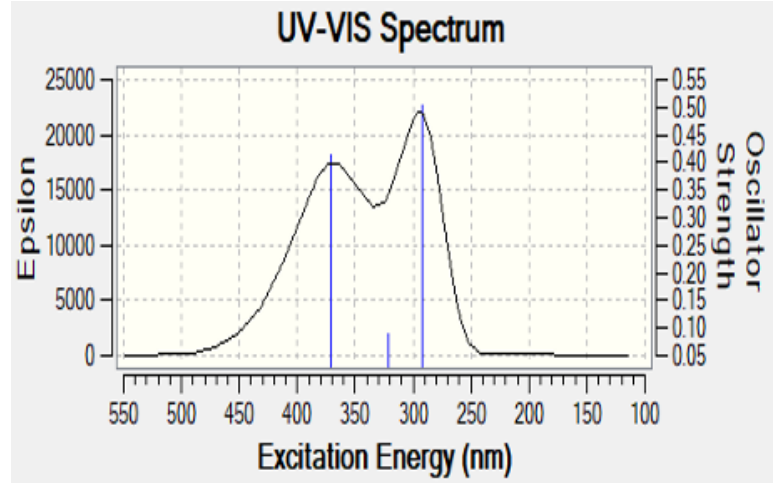

T4

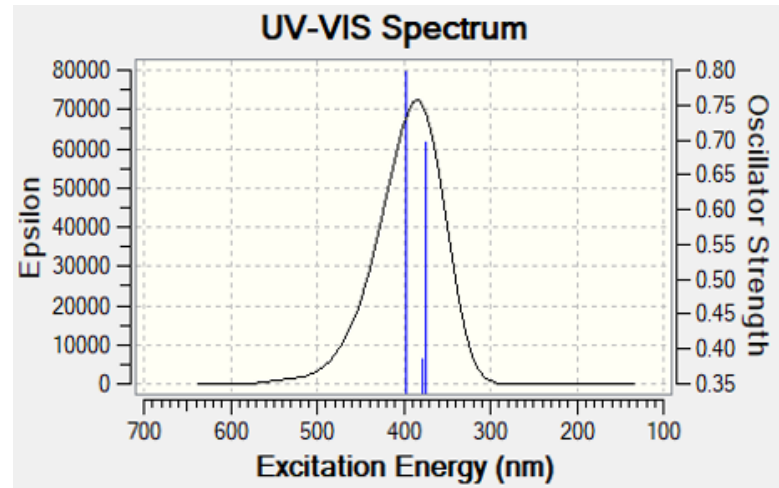

T5

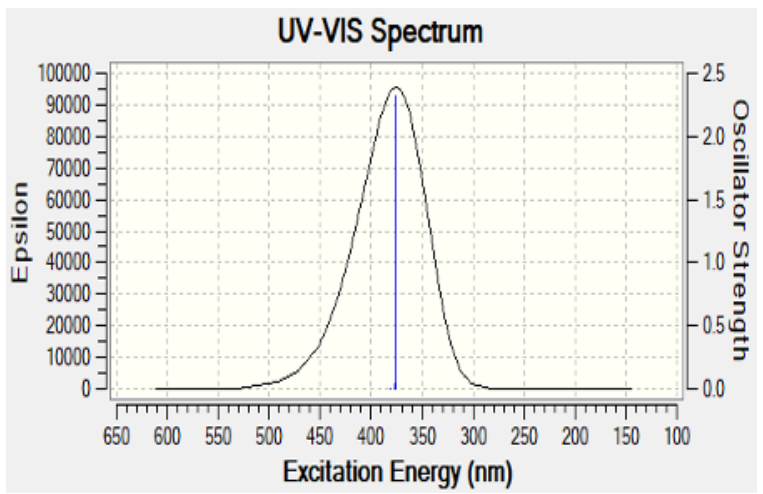

Fig. 5. Computed UV-vis spectra of the examined molecules (T1, T2, T3, T4 and T5) by DFT/B3LYP/6-31(G) ZINDO method.

\section{CONCLUSION}

The geometric parameters of the four Thienothiophene-based $\pi$-conjugated organic compounds (T1, T2, T3, T4 and T5) were obtained by B3LYP / 6-31G (d) calculations. The gap energy calculated with the same method decreases when a base (thienothiophene) is added for all the molecules. Is basically due to the stabilization of the LUMO level and destabilization of the HOMO level of several compounds leads the reduction of energy gaps HOMO - LUMO. Regarding the T5 the reduction of the observed energy deficit is likely to guarantee the best electronic properties of the 
corresponding polymers. These results showed that the T5 is promising material for optoelectronic application.

\section{REFERENCES}

1. Sonniger Rekord: Durchbruch für die HybridSolarzelle, article du centre de recherche sur les matériaux (FMF) ; 2010/02/01

2. Des scientifiques renforcent l'efficacité des cellules solaires, Article cordis ; 2010/02/17

3. H. Zgou, S. Boussaidi, A. Zahlou, m. Bouachrine, M. Hamidi, International Journal of Advanced Research in Computer Science and Software Engineering, 45 (2014) 10-19.

4. P.Damman, M.Dosière, M. Brunel, J.C.Wittmann, J. Am. Chem. Soc., 1997, 119, 4633.

5. S. Hotta, T.Katagiri, J. Heterocycl. Chem., 2000, 40, 845.

6. H. Zgou, M. Hamidi, M. Bouachrine, Journal of molecular Structure: Theochem. 2007, 814, 2532.

7. M. Amine, M. Hamidi, S.M. Bouzzine, A. Amine, M. Bouachrine, Adv. Mat. Lett., 2012, 3(1), 15-20.

8. L. L. Chua, J. Zaumseil, J. F. Chang, E. C. W. $\mathrm{Ou}$, P. K. H. Ho, H. Sirringhaus, R. H. Friend, nature, 2005, 434, 194-199.

9. S. M. Bouzzine, S. Bouzakraoui, M. Bouachrine, M.Hamidi, Journal of Molecular Structure: THEOCHEM. 2005, 726, 271-276.

10. C. Ego, D. Marsitzky, S. Becker, J. Y. Zhang, A. C. Grimsdale, K. Mullen, J. D. MacKenzie, C. Silva, R. H. Friend, J. Am. Chem. Soc., 2003, $125,437-443$.

11. J. Liu, X. Guo, L. J. Bu, Z. Y. Xie, Y. X. Cheng, Y. H. Geng, L. X. Wang, X. B. Jing, F. S. Wang, AdvFunct Mater, 2007, 17, 1917-1925.

12. W. C. Wu, C. L. Liu,W. C. Chen, Polymer, 2006, 47, 527-538.

13. W. H. Tang, T. T. Lin,L. Ke, Z. K. Chen,J Polym Sci Part A: Polym Chem.,2008, 46, 7725-7738.

\section{Acknowledgments}

The authors are grateful to the "Association Marocaine des Chimistes Théoriciens (AMCT)" for help on computation software.

14. G. Dennler, M. C.Scharber, T. Ameri, P. Denk, K. Forberich, C. Waldauf, C. Brabec, J. Adv. Mater.,2008, 20, 579-583.

15. K. Hara, M.Kurashige, Y. Dan-Oh, C. Kasada,A. Shinpo, S. Suga, K. Sayama, H. Arakawa,New J. Chem.,2003, 27, 783.

16. C. M. Carcel, J. K. Laha , R. S. Loewe,P. Thamyongkit, K.-H.Schweikart, V. Misra, D. F. Bocian,J. S. Lindsey,J. Org.Chem.,2004, 69, 6739-6750.

17. A. A. Yasseri, D.Syomin,R. S. Loewe, J. S. Lindsey, F. Zaera, D. F. Bocian, J. Am. Chem.Soc.,2004, 126, 15603-15612.

18. B. Chandrakantha, Arun M. Isloor, Kishore Sridharan, Reji Philip,PrakashShetty, Mahesh Padaki, Arabian Journal of Chemistry, 2013, 6, 97-102.

19. A.J. Heeger, J. Orenstein, D. Ulrich (Eds.), Nonlinear Optical Properties of Polymers, vol. 109, Materials Research Society, Pittsburgh, 1988.

20. Sadiq M-H. Ismael, Kawkab A. Hussain, Hasanain A S. A Majeed,Der Pharmacia Lettre, 2012, 4, (6), 1826-1831.

21. I.A. Adejoro,O. E. Oyeneyin, O.O. Adeboye, J. A. Obaleye,J. Comput. Methods Mol. Des., 2012, 2 (4):142-148.

22. E.E. Havinga, T. Hoeve, H. Wynberg, Synth. Met., 1993, 55, 299.

23. V.A. Rassolov, M.A. Ratner, J.A. Pople, P.C. Redfern, L.A. Curtiss, J. Comp. Chem.,2001, 22, 976.

24. A.D. Becke, J. Chem. Phys., 1993, 98, 5648.

25. C. Lee et al. Phys. Rev. B, 1988, 37, 785.

26. M.A. D’Oliveira, H.A. Duarte, J.M. Pernant, W.B. D'Almeida, J.Phys. Chem., 2000, A104, 8256. 